\title{
Pain in the groin: mycotic aneurysm after transcutaneous aortic valve replacement
}

\author{
Austin Jacobs, ${ }^{1}$ Sebastian Ochoa, ${ }^{1}$ Fady Hannah-Shmouni ${ }^{2}$
}

'Department of Medicine, MedStar Georgetown University Hospital, Washington, District of Columbia, USA

${ }^{2}$ Clinical Biochemical Genetics, The Hospital for Sick Children, University of Toronto, Toronto, Ontario, Canada

\section{Correspondence to} Dr Austin Jacobs, austin.jacobs@gunet. georgetown.edu

Accepted 20 July 2017

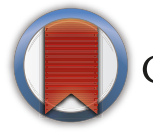

CrossMark

To cite: Jacobs A, Ochoa S, Hannah-Shmouni F. BMJ Case Rep Published Online First: [please include Day Month Year]. doi:10.1136/bcr-2017 220626

\section{DESCRIPTION}

An 88-year-old man with controlled hypertension, coronary artery disease and atrial fibrillation on warfarin therapy presented to the emergency department for evaluation of a right groin pain and fall. He had undergone a transcatheter aortic valve replacement (TAVR) for severe aortic stenosis a month prior to presentation. The procedure was complicated by a cerebrovascular accident. He was febrile and tachycardic, with a right-sided ptosis, facial droop and a pulsatile mass in the right groin

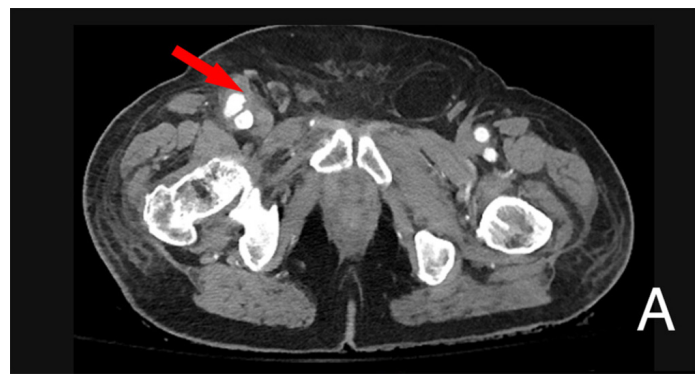

Figure 1 New right common femoral mycotic aneurysm (arrow) confirmed on abdominal CT.

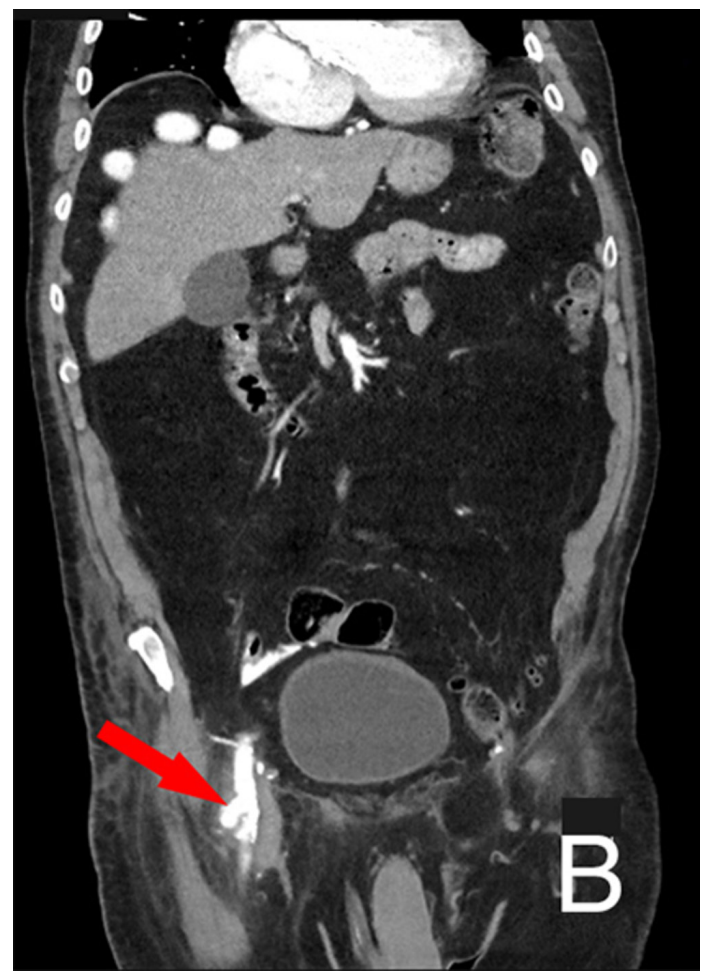

Figure 2 New right common femoral mycotic aneurysm (arrow) confirmed on abdominal CT.

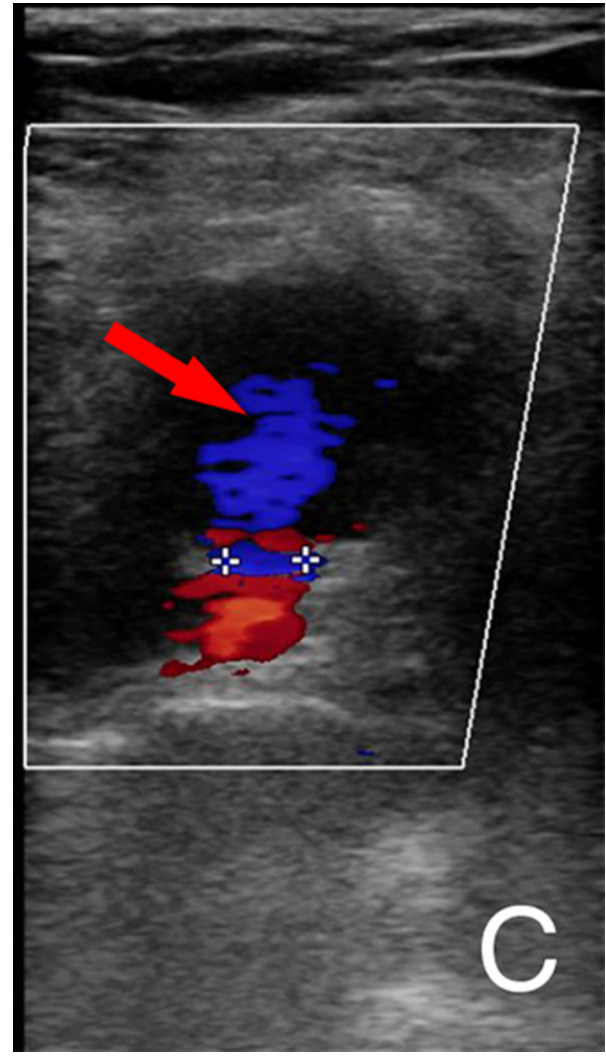

Figure 3 New right common femoral mycotic aneurysm (arrow) confirmed on ultrasound.

(access site during TAVR). Laboratory evaluation revealed mild leucocytosis $\left(12,4.23-9.07 \times 10^{9} / \mathrm{L}\right)$. A new right common femoral mycotic aneurysm was confirmed on abdominal CT (figures 1 and 2) and ultrasound (figure 3 ). Within 12 hours, blood cultures grew gram-negative rods, later speciated to Pseudomonas aeruginosa. He was started on empiric vancomycin and piperacillin-tazobactam for suspected sepsis. Evaluation for endocarditis with a transoesophageal echocardiogram did not reveal valvular vegetations. He underwent an excision of the right femoral mycotic aneurysm with a sartorius muscle flap. Pathology revealed an inflamed pseudoaneurysm with atherosclerosis. Ceftazidime was successfully continued for 6 weeks.

Mycotic aneurysm is an abnormal focal arterial dilation due to bacteraemia or septic embolisation. ${ }^{1}$ The most commonly affected sites are the femoral artery $(38 \%)$ and abdominal aorta $(31 \%)^{2}{ }^{3}$ Mycotic aneurysm causes degeneration of the arterial wall from inflammation, which carries a high risk of rupture and mortality. ${ }^{1}$ The predominant organisms in mycotic aneurysms are Staphylococcus 
aureus and Salmonella species. Complications of TAVR include vascular access site morbidity (bleeding, vessel perforation, infection), ventricular wall perforation, valvular complications, arrhythmias, cerebrovascular accident and myocardial infarction. To the best of our knowledge, this is the first report of a $P$. aeruginosa aneurysm following TAVR, possibly due to bacterial inoculation during instrumentation.

Contributors FH-S contributed to the planning, conduct, reporting, conception and design, acquisition of data or analysis and interpretation of data. AJ contributed to the planning, conduct, reporting, conception and design, acquisition of data or analysis and interpretation of data. SO contributed to the planning, conduct, reporting, conception and design, acquisition of data or analysis and interpretation of data.

Competing interests None declared.

Patient consent Obtained.

Provenance and peer review Not commissioned; externally peer reviewed.

(c) BMJ Publishing Group Ltd (unless otherwise stated in the text of the article) 2017. All rights reserved. No commercial use is permitted unless otherwise expressly granted.

\section{Learning points}

- Complications of transcatheter aortic valve replacement include vascular access site morbidity (bleeding, vessel perforation, infection), ventricular wall perforation, valvular complications, arrhythmias, cerebrovascular accident and myocardial infarction.

- Mycotic aneurysm (aneurysms arising from infection of the arterial wall) causes degeneration of the arterial wall from inflammation associated with infection from either bacteraemia or septic embolisation.

\section{REFERENCES}

1 Leo PJ, Pearl J, Tsang W, et al. Mycotic aneurysm: a diagnostic challenge. Am J Emerg Med 1996;14:70-3.

2 Joffe II, Emmi RP, Oline J, et al. Mycotic aneurysm of the descending thoracic aorta: the role of transesophageal echocardiography. J Am Soc Echocardiogr 1996;9:663-7.

3 Gomes MN, Choyke PL, Wallace RB, et al. Infected aortic aneurysms. A changing entity. Ann Surg 1992;215:435-42.

Copyright 2017 BMJ Publishing Group. All rights reserved. For permission to reuse any of this content visit http://group.bmj.com/group/rights-licensing/permissions.

BMJ Case Report Fellows may re-use this article for personal use and teaching without any further permission.

Become a Fellow of BMJ Case Reports today and you can:

- Submit as many cases as you like

- Enjoy fast sympathetic peer review and rapid publication of accepted articles

- Access all the published articles

Re-use any of the published material for personal use and teaching without further permission

For information on Institutional Fellowships contact consortiasales@bmjgroup.com

Visit casereports.bmj.com for more articles like this and to become a Fellow 